\title{
DETERMINATION OF THE BREAKPOINTS AND THE PARENTAL ORIGIN OF A RING 22 CHROMOSOME: AN ANALYSIS BY HIGH-RESOLUTION BANDING TECHNIQUE, QUINACRINE AND SILVER STAININGS
}

\author{
Kenji Naritomi and Kiyotake Hirayama \\ Department of Pediatrics, School of Medicine, University of the Ryukyus, \\ 207 Uehara, Nishihara, Okinawa 903-01, Japan
}

\begin{abstract}
Summary A 2-year-old girl with r(22) syndrome is presented. Highresolution banding technique and silver staining of nucleolus organizing regions (NORs) were used to define its breakpoints. The breakpoint in the long arm was verified to locate at most distal segment (q13.3) by Gand R-bandings. The breakpoint in the short arm was verified to locate at p13, because the $\mathrm{r}(22)$ had an almost normal NOR compared to normal homolog 22. The karyotype was designated as 46,XX,r(22) (p13q13.3). Origin of the ring(22) was estimated to be of paternal by an analysis of Qband heteromorphism.
\end{abstract}

\section{INTRODUCTION}

The first observation of a ring chromosome 22 was by Weleber et al. (1968), which was verified as $\mathrm{r}(22)$ later by Magenis et al. (1972). Rethoré et al. (1976) proposed $\mathrm{r}(22)$ syndrome from 14 observations, and Hunter et al. (1977) summarized phenotypic correlations on 21 patients with the $\mathrm{r}(22)$. We here report a girl with a r(22). Its breakpoints were analyzed by high-resolution banding technique and silver staining of nucleolus organizing regions (NORs), and origin of the $r(22)$ was estimated by Q-band heteromorphism.

\section{CASE REPORT}

The propositus was the first child born to healthy nonconsanguineous parents when the mother was 19 and the father was 23 years old. The pregnancy was uncomplicated. There was no known parental exposure to mutagenic agents. She was born at 41 th week of gestation. The delivery was complicated with weak labor pains and premature rupture of membrane, but asphyxia was not noted. Birth

Received May 11, 1987; revised version received September 4, 1987; Accepted October 7, 1987 


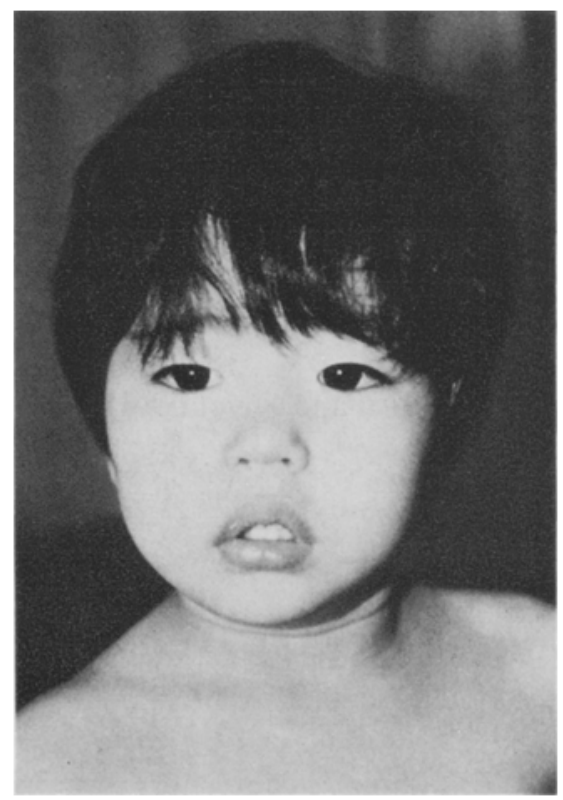

Fig. 1. The propositus at 2 years old. Note full eyebrows, epicanthal folds, low nasal bridge, full lips and micrognathia.

weight was $3,000 \mathrm{~g}$. Cleft soft palate was noted soon after birth. Microcephaly, developmental retardation and hypotonia were pointed out at six months of age. At 18 months of age when she took a verbal training because of speech retardation, plastic surgery for cleft soft palate was recommended. She was referred to our clinic for preoperative examination at two years of age.

At the first visit to our clinic, her physical growth was not so retarded except microcephaly; height was $82.5 \mathrm{~cm}(-0.6 \mathrm{SD})$, weight $9,340 \mathrm{~g}(-1.5 \mathrm{SD})$ and head circumference $42.2 \mathrm{~cm}(-3 \mathrm{SD})$. She could not speak even a word. Unsteady ataxic gait was noted. Physical examination revealed mild synophrys, epicanthal folds, cleft soft palate, high-arched palate, low nasal bridge, thick full lips, micrognathia, small umbilical hernia, clinobrachydactyly of 5 th fingers, bilateral cutaneous syndactyly between 2nd and 3rd toes and hypotonia (Fig. 1). Dermatoglyphic examination revealed one arch and nine ulnar loop patterns. Bilateral distal axial triradii $\left(t^{\prime}\right)$ was observed. There was no abnormal findings in routine laboratory examinations, brain CT-scanning, electroencephalography, echocardiography and intravenous pyelography.

\section{CYTOGENETICS}

Chromosomes of the propositus and the parents were analyzed on lymphocytes obtained by conventional whole blood cultures for $72 \mathrm{hr}$. The cells for high-resolu- 
tion banding were obtained by a modification of ethidium bromide treatment (Ikeuchi and Sasaki, 1979).

In GTG banding preparations, the propositus had 46 chromosomes with a tiny $\mathrm{r}(22)$ in 90 cells. In two cells a double sized ring chromosome 22 were observed. 45 chromosomes missing one chromosome 22 were observed in other eight cells. High-resolution GTG, RHG, CBG banding and Ag-NORs staining (Bloom and Goodpasture, 1976) were studied to analyze its breakpoints precisely. Ag-NORs stained preparates were treated with trypsin to distinguish 22 from 21. As shown in partial karyotypes of $G$ and $R$ bandings, a breakpoint in the long arm was verified to locate at most distal segment, 22q13. In Ag-NORs staining size of NOR of $\mathrm{r}(22)$ was almost as same as that of its normal homolog. The breakpoint in the short arm seemed to locate at 22p13, because Ag-NORs stain the stalk of acrocentric chromosomes, and Ag-NOR of a r(22) was considered to be intact (Fig. 2). The

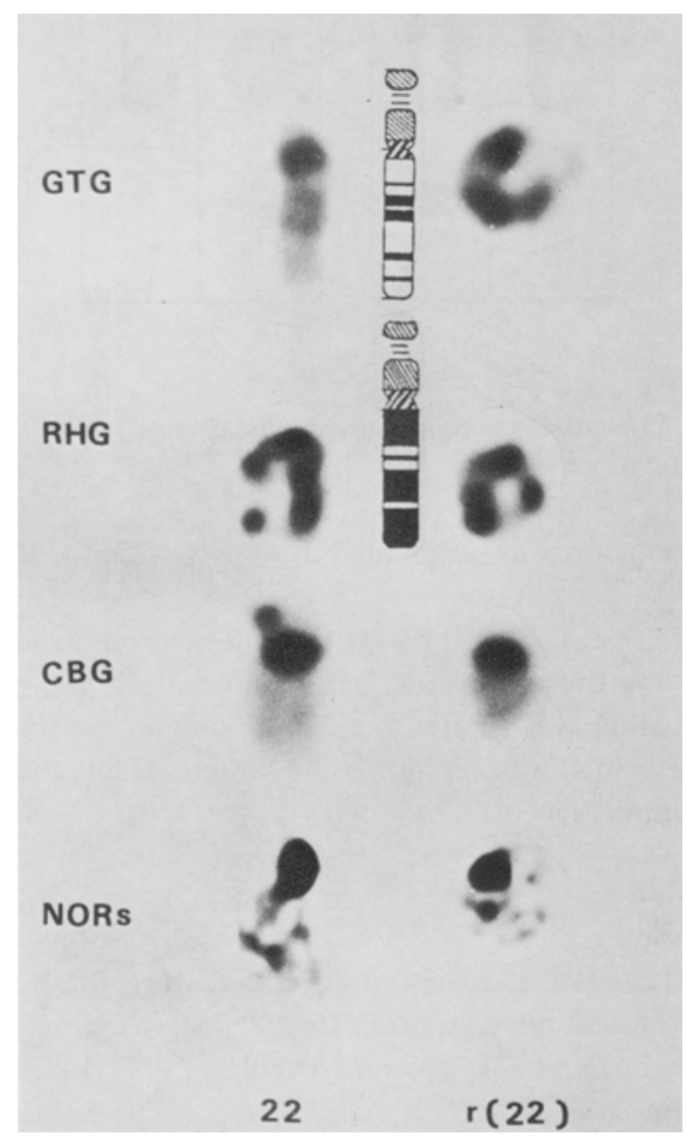

Fig. 2. Partial karyotypes of the propositus. NOR of $\mathrm{r}(22)$ was almost as same as NOR of normal bomolog. 


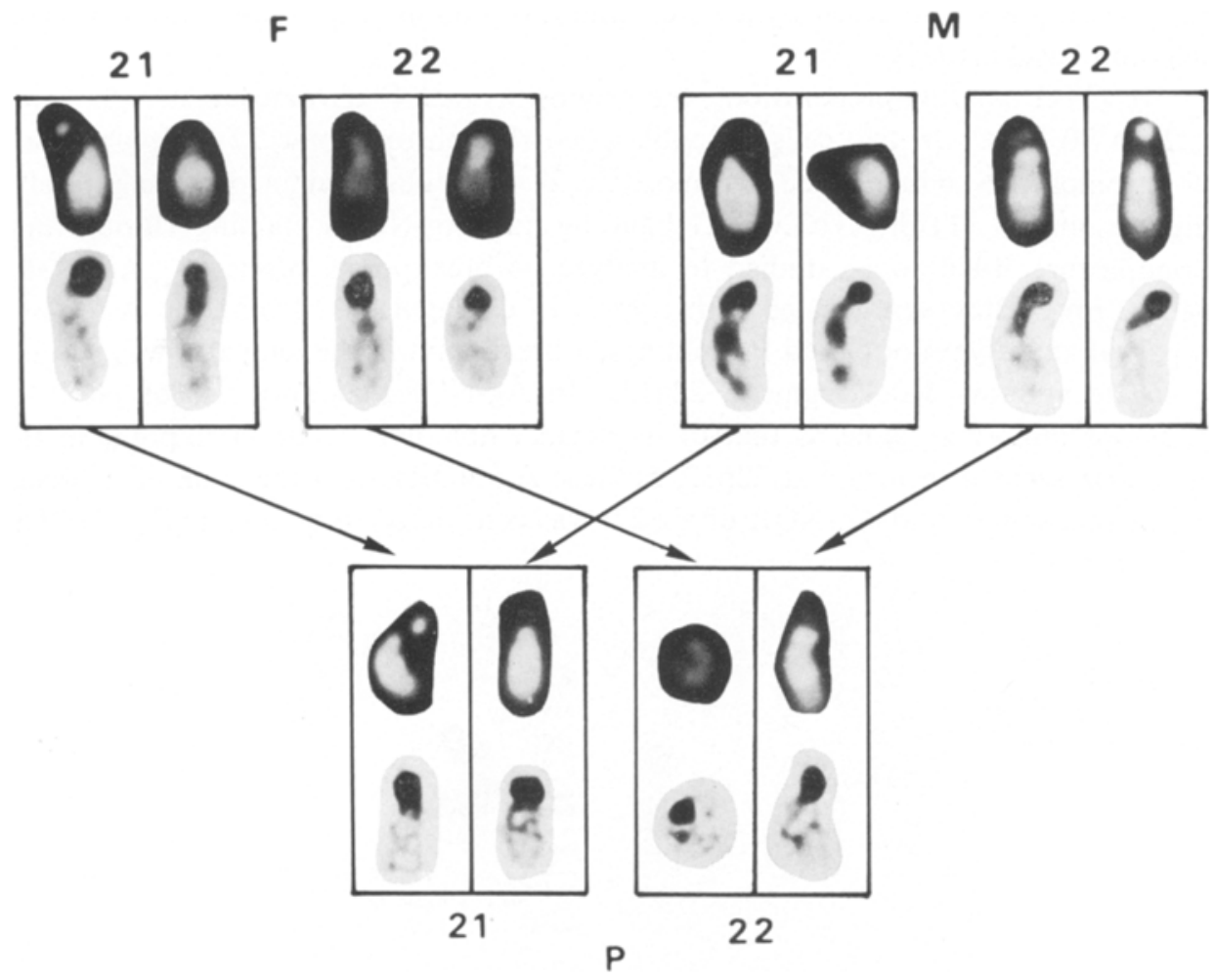

Fig. 3. QFQ and Ag-NOR of the propositus and the parents. Note $r(22)$ seems to be of paternal origin (see text).

karyotype of the propositus was designated as $46, \mathrm{XX}, \mathrm{r}(22)(\mathrm{p} 13 \mathrm{q} 13.3)$. The parents had normal karyotypes.

Origin of this $\mathbf{r}(22)$ was studied by QFQ-band heteromorphism of the short arm of chromosome 22 . In the propositus, p11 of normal 22 had medium fluorescence with a pale satellite, which was similar to a 22 homolog of the mother. Fluorescence of the $r(22)$ was pale, which was similar to the father. Thus the $r(22)$ was estimated to be of paternal origin (Fig. 3).

\section{DISCUSSION}

Since Hunter et al. (1977) reviewed clinical features of $r(22)$ syndrome on 21 cases, additional 17 cases have, to our knowledge, been reported including the present case (Palmer et al., 1977; Howard-Peebles, 1977; Funderburk et al., 1979; Faed et al., 1979; Fryns et al., 1979; Aller et al., 1979; Sakuragawa et al., 1979; Fowler et al., 1980; Kondo et al., 1980; Stoll and Roth, 1983; Reeve et al., 1985). As mentioned by Funderburk et al. (1979), there is considerable variability in its 
expression from normal mentality to profound mental retardation with multiple minor anomalies.

The clinical findings recognized in $50 \%$ or more of the patients are mental or developmental retardation, poor weight gain, microcephaly, epicanthal folds, full eyebrows (synophrys), large ears with abnormal auricle, dental malocclusion, thick lips, syndactyly between 2nd and 3rd toes, hypotonia, unsteady gait, hyperreflexia, abnormal EEG findings and distal axial triradius. Findings recognized in 10 to $50 \%$ of the patients are feeding difficulty, short stature, abnormal cranium, maxillary hypoplasia, hypertelorism, ptosis of eyelids, low-set ears, low nasal bridge, micrognathia, high-arched palate, vertebral anomaly, brachydactyly, syndactyly (finger), hypertonia, seizures, arch dermal ridge pattern and radial loop pattern (Table 1). Rethoré et al. (1976) pointed out almond-shaped palpebral fissures (doe's eyes) as a cardinal finding of $\mathbf{r}(22)$ syndrome, but it was not mentioned by other investigators. Major malformations are exceptional.

The $r(22)$ chromosome seems to be stable. All cells had a r(22) in 20 cases

Table 1. Clinical findings of $r(22)$ syndrome in 34 cases reported.

\begin{tabular}{lclr}
\hline \multicolumn{1}{c}{ Findings } & No. $(\%)$ & \multicolumn{1}{c}{ Findings } & No. $(\%)$ \\
\hline Mean maternal age $(\mathrm{y} / \mathrm{o})$ & 25.83 & Low nasal bridge & $9 / 28(32.1)$ \\
Mean paternal age $(\mathrm{y} / \mathrm{o})$ & 29.72 & Large mandible & $3 / 25(12.0)$ \\
Normal gestational age & $24 / 25$ & Micrognathia & $7 / 25(28.0)$ \\
Mean birth weight $(\mathrm{g})$ & 2,960 & High-arched palate & $11 / 26(42.3)$ \\
Sex ratio $(\mathrm{M} / \mathrm{F})$ & $16 / 18$ & Dental malocclusion & $7 / 13(53.8)$ \\
Feeding difficulty & $9 / 21(42.9)$ & Thick lips & $13 / 17(76.5)$ \\
Developmental delay & $27 / 30(90.0)$ & Vertebral anomaly & 8 \\
Height (3p) & $5 / 29(17.2)$ & Syndactyly $(2-3$ toes $)$ & $12 / 20(60.0)$ \\
$\quad(10 \mathrm{p})$ & $10 / 29(34.5)$ & Brachydactyly $(5$ th) & $7 / 22(31.8)$ \\
Weight (3p) & $10 / 30(29.4)$ & Syndactyly (finger) & 4 \\
$\quad(10 \mathrm{p})$ & $17 / 30(56.7)$ & Lymphoedema & 3 \\
Head circumference $(3 \mathrm{p})$ & $12 / 29(41.4)$ & Hypotonia & $15 / 20(75.0)$ \\
& $19 / 29(65.5)$ & Hypertonia & $3 / 20(15.0)$ \\
Abnormal cranium & $8 / 23(34.8)$ & Unsteady gait & $13 / 15(86.7)$ \\
Maxillary hypoplasia & 5 & Hyporeflexia & $2 / 13(15.4)$ \\
Epicanthal folds & $19 / 22(86.4)$ & Hyperreflexia & $7 / 13(53.8)$ \\
Hypertelorism & $7 / 25(28.0)$ & Abnormal EEG & $8 / 16(50.0)$ \\
Full eyebrows & $14 / 14(100)$ & Seizures & $7 / 18(38.9)$ \\
Long eyelashes & $5 / 7(71.4)$ & Arch pattern & $7 / 23(30.4)$ \\
Ptosis & 4 & Radial loop pattern & $10 / 23(43.5)$ \\
Large ears & $16 / 22(72.7)$ & Distal triradius & $15 / 23(65.2)$ \\
Abnormal auricle & $11 / 13(84.6)$ & & \\
Low-set ears & $4 / 23(17.4)$ & & \\
\hline
\end{tabular}

Cases 2 to 5 reported by Stoll and Roth was eliminated. 
out of 38 cases reported. A double sized $r(22)$ was observed in 1 to $2 \%$ of the cells in three cases (Palmer et al., 1977; Aller et al., 1979 and present case). Mosaicism of $\mathrm{r}(22)$ with 22 monosomy was highly dominant in most of the cases. Exceptional cases were reported by Stoll and Roth (1983). They made a segregation analysis of $\mathrm{r}(22)$ with familial transmission. All five cases with $\mathrm{r}(22)$ had a mosaicism with 22 monosomy (ratio was nearly $1 / 1$ ), and only propositus had mental retardation and microcephaly.

Severity of microcephaly may be related to the ratio of $\mathrm{r}(22)$. In 38 cases of $\mathrm{r}(22)$ including the present case, $30 \mathrm{had}$ a $\mathrm{r}(22)$ in more than $90 \%$ of the cells counted. Percentile figures of head circumference were described in 26 cases. Severe microcephaly (head circumference less than 3rd percentile) was found in 12 cases $(46 \%)$. On the other hand, microcephaly was not noticed in eight cases which showed $\mathrm{r}(22)$ in less than $70 \%$ of the cells.

Silver staining of NOR in chromosome 22 was studied in three cases (Funderburch et al., 1979; Fowler et al., 1980 and Stoll and Roth, 1983). There was no NOR of a $r(22)$ in all three cases. The breakpoint of the short arm was defined as 22p12. But in the present case, the finding was different from these three cases. NOR was observed in the $r(22)$, and its size was almost as same as that of a normal homolog. The breakpoint was considered to locate at $22 \mathrm{p} 13$, most distal segment of the short arm. Ag-NORs staining of the double sized ring could not be permitted to analyze, because its population was very small.

The breakpoint of the long arm was defined at q13 in most of the cases. The clinical findings of $r(22)$ syndrome is presumably due to loss of material from the long arm, because the short arm of chromosome 22 is known to be dispensable without ill effects, e.g., Robertsonian translocation. In the present case, high-resolution GTG and RHG bandings were used to study the breakpoint of the long arm, and it was verified to locate at q13.3. The very distal segment of the long arm of chromosome 22 was deleted. The $\mathrm{r}(22)$ of the present case was presumed to arise from two breaks occurred at most distal segments of the short and the long arms and reunion of them.

Origin of a $\mathrm{r}(22)$ was studied in only two case (Case 1 of Funderburk et al., 1979 and Fowler et al., 1980) using sequential quinacrine and silver staining. Funderburk et al. (1979) could not estimate its origin, but Fowler et al. (1980) estimated it was of maternal origin. In the present case, however, the origin of a $r(22)$ was estimated to be of paternal.

\section{REFERENCES}

Aller, V., Abrisqueta, J.A. de Torres, M.L., Martin-Licas, M.A., Perez-Castillo, A., and Del Mazo, J. 1979. An $\mathrm{r}(22)$ (p11-q13) in a moderately mentally retarded girl. Hum. Genet. 51: 157162.

Bloom, S.E. and Goodpasture, C. 1976. An improved technique for selective staining of nucleolar organizer regions in human chromosomes. Hum. Genet. 34: 199-206. 
Faed, M.J.B., Robertson, J., Field, M.A.S., and Mellon, J.P. 1979. A chromosome survey of a hospital for the mentally subnormal. Clin. Genet. 16: 191-204.

Fowler, G., Kaiser-McCaw, B., and Hecht, F. 1980. The use of sequential silver and quinacrine staining to determine the parental origin and breakpoints of a ring-22 human chromosome. Clin. Genet. 18: 274-279.

Fryns, J.P. and Van der Berghe, H. 1979. Ring chromosome 22 in a mentally retarded child and mosaic $45, \mathrm{XX},-15,-22,+(15 ; 22)(\mathrm{p} 11 ; \mathrm{q} 11) / 46, \mathrm{XX}, \mathrm{r}(22) / 46, \mathrm{XX}$ karyotype in the mother. Hum. Genet. 47: 213-316.

Funderburk, S.J., Sparked, R.S., and Klisak, I. 1979. Phenotypic variations in two patients with a ring chromosome 22. Clin. Genet. 16: 305-310.

Howard-Peebles, A.N. 1979. Indication for chromosome analysis illustrated by a case of ring 22. J. Hered. 68: 268-269.

Hunter, A.G., Ray, M., Wang, H.S., and Thompson, D.R. 1977. Phenotypic correlations in patients with ring chromosome 22. Clin. Genet, 12: 239-249.

Ikeuchi, T. and Sasaki, M. 1979. Accumulations of early mitotic cells in ethidium bromide-treated human lymphocyte cultures. Proc. Jpn. Acad. 55B: 15-18.

Kondo, I., Hamaguchi, H., Nakajima, S., and Haneda, T. 1980. A cytogenetic survey of 449 patients in a Japanese institutions for the mentally retarded. Clin. Genet. 17: 177-182.

Magenis, R.E., Armendares, S., Hecht, F., Weleber, R.G., and Overton, K. 1972. Identification by fluorescence of two $\mathrm{G}$ rings: $(46, X Y, 21 \mathrm{r}) \mathrm{G}$ deletion syndrome $\mathrm{I}$ and $(46, X X, 22 \mathrm{r}) \mathrm{G}$ deletion syndrome II. Ann. Génét. 15: 265-266.

Palmer, C.G., Hodes, M.E., Reed, T., and Kojetin, J. 1977. Four new cases of ring 21 and ring 22 including familial transmission of ring 21. J. Med. Genet. 14: 54-60.

Reeve, A., Shulman, S.A., Zimmerman, A.W., and Cassidy, S.B. 1985. Methylphenidate therapy for aggression in a man with ring 22 chromosome. Arch. Neurol. 42: 69-72.

Rethoré, M.O., Noel, B., Couturier, J., Prieur, M., Lafourcade, J., and Lejeune, J. 1976. Le syndrome r(22). A propos de quatre nouvelle observations. Ann. Génét. 19: 111-117.

Sakuragawa, N., Adachi, K., Hayashi, M., and Fukuhara, N. 1979. Neurological complications of the ring(22) syndrome: A case report. Brain Develop. 1: 91-96.

Stoll, C. and Roth, P.-M. 1983. Segregation of a 22 ring chromosome in three generations. Hum. Genet. 63: 294-296.

Weleber, R.G., Hecht, F., and Gilbett, E.R. 1968. Ring-G chromosome, a new G-deletion syndrome? Am. J. Dis. Child 115: 489-493. 